\title{
Gland of Littre
}

National Cancer Institute

\section{Source}

National Cancer Institute. Gland of Littre. NCI Thesaurus. Code C49311.

Any of the glands located at the wall of the urethra of male mammals that produce and secrete mucus, a major component of semen. 